\title{
Nonenzymatic Browning Reactions of Dihydroxyacetone with Amino Acids or Their Esters
}

\author{
Keisuke Kawashima, Hiroshi Itoh and Ichiro Chibata \\ Research Laboratory of Applied Biochemistry, Tanabe Seiyaku Co. Ltd., \\ 16-89, Kashima 3-chome, Yodogawa-ku, Osaka 532, Japan
}

Received February 15, 1980

\begin{abstract}
Nonenzymatic browning reactions between dihydroxyacetone (DHA) and amino acids were investigated using buffers as solvents. Regardless of the type of amino acid, DHA was much more reactive than glucose or xylose. Among amino acids tested, lysine was most reactive. The rate of browning was maximum around a DHA-amino acid molar ratio of 1.5 , when the total concentration of DHA plus amino acid was constant at $0.1 \mathrm{M}$.

When aqueous alcohols were used as solvents, the browning intensity in the reaction between DHA and proline or amino acid ester increased exponentially with a decrease in water content.
\end{abstract}

Nonenzymatic browning reactions between sugars and amino acids through the Maillard reaction is well known to be responsible for many noxious changes of the essential amino acids including the development of brown discoloration and destruction. ${ }^{1.2)}$ However, there is also an increasing interest in the browning reaction which may contribute to the formation of flavor, ${ }^{3}$ antioxidant, ${ }^{4)}$ preservatives $^{5)}$ and coloring materials. ${ }^{6)}$ Most of the works on the browning reaction so far reported have been concerned with pentoses or hexoses as the sugar reactant.

In recent years, dihydroxyacetone (DHA), a triose, has been attracting considerable attention as a reactant in the browning reactions. Meybeck ${ }^{7}$ studied on the reaction products of DHA with amino acids by the spectroscopic method, and suggested that the products were conjugated polymers. Substances prepared by the reactions of DHA with valine ${ }^{8)}$ and with phenylalanine $e^{9)}$ were patented as a flavor enhancer of tobacco and a honey-like flavorant, respectively. In previous papers, ${ }^{10,11)}$ we reported the antioxidant properties of the browning products prepared from DHA and amino acids. However, there has been a lack of systematic study on the reaction of DHA with amino acids. The present paper describes the browning reaction between DHA and amino acids or their esters, using buffers and aqueous alcohols as solvents. In additon, this study also intends to focus on the influence of water on the browning rate.

\section{MATERIALS AND METHODS}

Materials. All amino acids (L-form) and DHA are products of Tanabe Seiyaku Co. Ltd., Osaka, Japan. Amino acid esters were prepared by the conventional esterification procedure. ${ }^{12)}$ All other chemicals were the reagent grade.

Browning reaction in buffer solutions. Sugar and amino acid were dissolved at a final concentration of $5 \times 10^{-2} \mathrm{M}$, respectively in $10 \mathrm{ml}$ of $0.1 \mathrm{M}$ acetate, phosphate or borate buffer. The solution was sealed up in an ampule and heated at $100^{\circ} \mathrm{C}$ for $2 \mathrm{hr}$. Brown color thus developed was read at $490 \mathrm{~nm}$, on a spectrophotometer, Varian Techtron, Model 635D, Varian Techtron Ltd., Melbourne, Australia. Solutions with absorbances greater than 1.0 were diluted with distilled water before measuring.

Browning reaction in aqueous alcohols. Prolin, glycine ethylester hydrochloride (Gly-OEt) or serine ethylester hydrochloride (Ser-OEt) and DHA were dissolved at a final concentration of $5 \times 10^{-2} \mathrm{M}$, respectively in $100 \mathrm{ml}$ of aqueous methanol (or ethanol) having various water contents. The solution was refluxed for $2 \mathrm{hr}$. The extinction value of the resulting colored solution was determined as described above. 


\section{RESULTS}

Effect of $\mathrm{pH}$ on the browning intensity in the reaction of reducing sugars with lysine

The browning rate of the reducing sugarlysine system was examined in buffer solutions of various pHs. Glucose, xylose and DHA were used as reducing sugars for the browning reaction. Lysine hydrochloride was chosen as a reactant amino acid since this amino acid had been known as the most reactive amino acid in the Maillard reaction. ${ }^{1)}$ Generally, as can be seen from Fig. 1, the rate of the

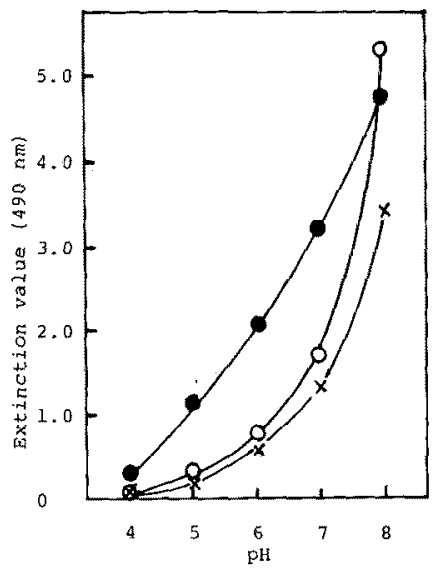

FIG. 1. Effect of $\mathrm{pH}$ on Browning Intensity in the Reaction of Reducing Sugars with Lysine.

Sugars and lysine hydrochloride were dissolved at each final concentration of $5 \times 10^{-2} \mathrm{M}$ in $10 \mathrm{ml}$ of $0.1 \mathrm{M}$ acetate ( $\mathrm{pH} 4.0$ and $\mathrm{pH} \mathrm{5.0),} \mathrm{phosphate} \mathrm{(} \mathrm{pH} 6.0$ and $\mathrm{pH} 7.0$ ) or borate $(\mathrm{pH} 8.0)$ buffers. The solutions were heated at $100^{\circ} \mathrm{C}$ for $2 \mathrm{hr}$ in sealed ampules.

- DHA; $\bigcirc$, xylose; $\times$, glucose.

browning reaction was accelerated with the increase in $\mathrm{pH}$. In the case of the DHA-lysine system, considerable browning occurred at such low pHs 4 and 5, and the intensity of browning increased almost linearly with increasing $\mathrm{pH}$. Although pigment formations in both the xylose-lysine and glucose-lysine systems were almost negligible at $\mathrm{pH} 4$, and slight at $\mathrm{pH} 5$, they increased significantly at higher pHs. In the following experiments, the browning reaction in buffers were performed at $\mathrm{pH}$ 7.0 .
Comparison of browning intensity in various combination of reducing sugars and amino acids

Browning intensities of various combinations of three reducing sugars and fourteen amino acids were determined in phosphate buffer $(\mathrm{pH} 7.0)$. The results are summarized in Fig. 2. Independent of the type of amino acids,

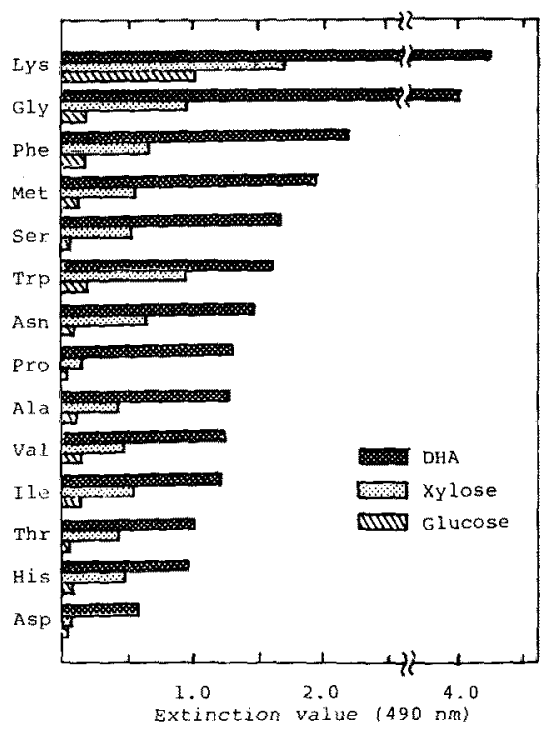

FIG. 2. Browning Intensity of the Reaction of Various Combinations of Reducing Sugars and Amino Acids.

The browning reaction was carried out at $\mathrm{pH} 7.0$. Other reaction conditions were the same as described in Fig. 1.

DHA produced the most intense color, followed by xylose and then glucose. Among the amino acids tested, lysine was most reactive, followed in a decreasing order by glycine, phenylalanine, methionine and serine. Even an acidic amino acid, aspartic acid, formed considerable browning color by reacting with DHA.

\section{Effect of $D H A$ /amino acid ratio on browning intensity}

Reaction systems with various DHA/amino (D/A) molar ratios were examined for the browning reaction. In these systems, the total concentration of DHA plus an amino acid was maintained constant at $0.1 \mathrm{M}$. Lysine, glycine and serine were selected as amino acid re- 


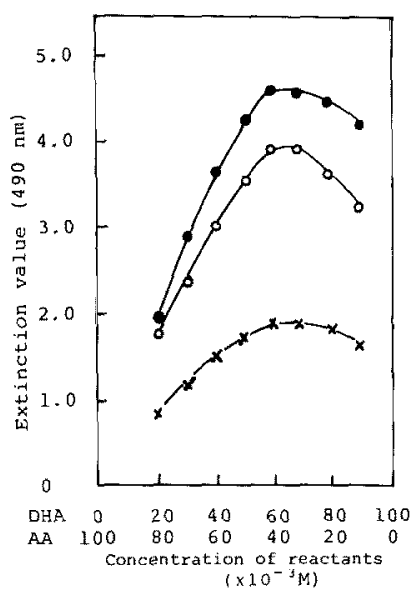

FIG. 3. Effect of Molar Ratio of DHA and Amino Acids (AA) on the Browning Intensity.

The total concentration of DHA plus an amino acid was maintained constant at $0.1 \mathrm{M}$. Other reaction conditions were the same as described in Fig. 2.

- lysine hydrochloride; $O$, glycine; $\times$, serine.

actants. The results are shown in Fig. 3. Until the D/A molar ratio reached $3 / 2$, the browning rate increased. The rate of pigment formation was maximum around the $\mathrm{D} / \mathrm{A}$ molar ratio of $3 / 2$. Above this ratio, the formation of the browning pigment decreased.

\section{Browning reaction of $D H A$ with proline in aqueous methanol}

The effect of water on the browning in-

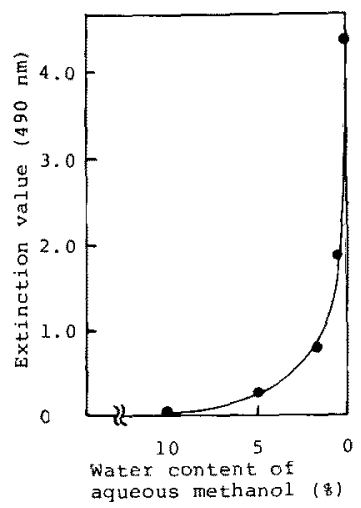

FIG. 4. Browning Reaction between DHA and Proline in Aqueous Methanol.

Proline and DHA were dissolved at each concentration of $5 \times 10^{-2} \mathrm{M}$ in $100 \mathrm{ml}$ of aqueous methanol. The solution was refluxed for $2 \mathrm{hr}$. The browning intensity was determined by absorbance at $490 \mathrm{~nm}$. tensity of DHA-proline was investigated by using aqueous methanol. As shown in Fig. 4, the browning rate was significantly influenced by the concentration of water in the reaction system. At $10 \%$ water concentration $(90 \%$ methanol), the rate of pigment formation was extremely low. At water concentrations of less than $5 \%$, the browning intensity increased exponentially with the decrease in water content in the solvent in spite of the lowering of the boiling point. The rate of browning was maximum in absolute methanol in which the browning rate was about 15 times higher than that in $95 \%$ methanol.

\section{Browning reaction of $D H A$ with amino acid esters in aqueous ethanol}

The effect of water content in aqueous ethanol on the browning intensity of the DHA-glycine ethylester or DHA-serine ethylester system was investigated. In these systems, as shown in Fig. 5, almost the same tendency as in the reaction in the DHA-prolinemethanol system was obserbed.

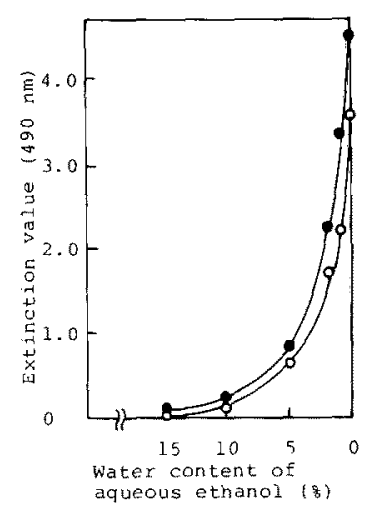

FIG. 5. Browning Reaction between DHA and Amino Acid Esters in Aqueous Ethanol.

Conditions of browning reaction was the same as described in Fig. 4.

o, serine ethylester hydrochloride; $O$, glycine ethyl ester hydrochloride.

\section{DISCUSSION}

The nonenzymatic browning reaction between sugars and amino acids is significantly 
affected by type of sugars. Pomeranz et al. ${ }^{13)}$ measured spectrophotometrically the browning rate of 20 sugars in combination with glycine or lysine in dilute buffered solutions heated at $114^{\circ} \mathrm{C}$ in an autoclave. They found that pentoses including xylose exhibited the highest reactivity among the sugars tested. In the present study, DHA was found to be much higher than xylose in the reactivity with lysine as well as with other amino acids (Figs. 1 and 2). Thus, the use of DHA as a suntansimulating cosmetic agent seems quite reasonable because DHA may be most reactive to amino acids in the browning reaction.

Warmbier et al. ${ }^{14)}$ studied the effect of glucose/lysine ratio on nonenzymatic browning kinetics, using a model system of intermediate moisture food (IMF). When lysine content was maintained constant, the browning rate increased as the initial molar ratio of glucose to lysine increased. The rate of pigment formation was found to approach a plateau when the initial glucose/lysine molar ratio was approximately three. The reason why the browning rate increased as the glucose level increased was suggested to be most likely due to its closer proximity to the amino groups, overcoming the greater diffusion barrier caused by the higher viscosity in the mode] food. In the case of our study, however, the browning rate was maximum at the $\mathrm{D} / \mathrm{A}$ molar ratio of 1.5 under the condition in which the total concentration of DHA and lysine was maintained constant in a buffer solution.

The nonenzymatic browning reaction is a major deteriorative reaction in $\mathrm{IMF}^{15}$, Therefore, the effect of water on the rate of browning reaction has been extensively studied by several workers. ${ }^{16,17)}$ Eichner and Karel $^{16)}$ observed that the browning rate decreased with the increase in water content, except in systems in which the mobility of reactants became substantially impeded at low water contents. Their liquid model system containing glycerol had a maximum of the browning intensity at a water activity $\left(a_{\mathrm{W}}\right)$ of 0.41 when stored at $37^{\circ} \mathrm{C}$. Warmbier et al. ${ }^{17}$ ) also reported the effect of $a_{\mathrm{w}}$ on the non- enzymatic browning reaction in an IMF model food system. They found the maximum rate of the browning pigment formation occurred at $a_{\mathrm{W}}$ range of $0.45 \sim 0.55$. However, the effect of water was complex and depended on the presence of various water-binding agents.

Generally, sugars are hardly soluble in nonaqueous organic solvents. Fortunately, DHA, a three-carbon keto sugar, is soluble in alcohols. Amino acids are also hardly soluble in non-aqueous solvents except proline which is soluble in methanol. Therefore, we considered that the DHA-proline-methanol system is suitable for the study of the effect of water on the browning rate. As shown in Fig. 4 , the maximum browning rate was seen in absolute methanol. This means that the browning reaction between sugars and amino acids may proceed at the maximum rate at $a_{\mathrm{w}}$ 0 as far as the reactants are completely solubilized. The inhibitory effect of water is considered to be due to the fact that water is a product of several condensation steps in the reaction.

DHA is produced industrially by the biochemical oxidation of glycerine ${ }^{18,19)}$ and commercially available. We hope the present study may contribute to extending the field of utilization of DHA and amino acids.

\section{REFERENCES}

1) I. Chibata, H. Itoh and K. Kawashima, Eiyo to Shokuryo, 19, 1 (1966).

2) K. Kawashima, H. Itoh and 1. Chibata, J. Agric. Food Chem., 26, 732 (1978).

3) J, E. Hodge, "Symposium on Foods: The Chemistry and Physiology of Flavors," H. W. Schulz, E. A. Day and L. M. Libbey, ed., Avi, Westport, Conneticut, 1967, p. 465.

4) K. Kawashima, H. Itoh and I. Chibata, New Food Industry, 19(7), 21 (1977).

5) N. Watanabe, Y. Hayakawa, M. Yajima and K. Sugitani, Japanese Pat., 48-14, 042 (1973).

6) I. Chibata, H. Itoh and K. Kawashima, Japanese Pat., Kokai 49-113,819 (1974).

7) A. Meybeck, J. Soc. Cosmet. Chem., 28, 25 (1977).

8) A. H. Warfield, W. D. Galloway and A. G. Kallianos, U.S. Pat,, 3,920,026 (1975) [C.A., 84, $71681 t(1976)]$. 
9) Fuji Oil Co. Ltd., British Pat., 1,357,511(1974)[C.A., 82, 71825 b (1975)].

10) H. Itoh, K. Kawashima and I. Chibata, Agric. Biol. Chem., 39, 283 (1975).

11) K. Kawashima, H. Itoh and I. Chibata, J. Agric. Food Chem., 25, 202 (1977).

12) J. P. Greenstein and M. Winitz, "Chemistry of the Amino Acids," vol. II, John Wiley \& Sons, Inc., New York, 1961, pp. 925 928.

13) Y. Pomeranz, J. A. Johnson and J. A. Shellenberger, J. Food Sci., 27, 350 (1962).

14) H. C. Warmbier, R. A. Schnickels and T. P. Labuza,
J. Food Sci., 41, 981 (1976).

15) M. Loncin, J. J. Bimbenet and J. Lenges, J. Food Technol, 3, 131 (1968).

16) K. Eichner and M. Karel, J. Agric. Food Chem., 20, $218(1972)$.

17) H. C. Warmbier, R. A. Schnickels and T. P. Labuza, J. Food Sci., 41, 528 (1976).

18) S. Yamada, K. Nabe, N. Izuo, M. Wada and I. Chibata, I. Ferment. Technol, 57, 215 (1979).

19) S. Yamada, K. Nabe, N. Izuo and I. Chibata, J. Ferment. Technol., 57, 221 (1979). 